\title{
Obesity and Bariatric Surgery awareness in the Kocaeli province, a leading industrial city in Turkey
}

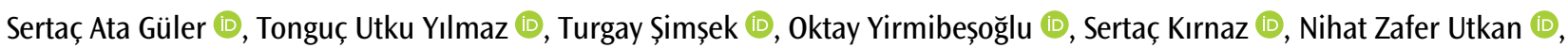
Nuh Zafer Cantürk (i)

ABSTRACT

ORCID IDs of the authors:

S.A.G. 0000-0003-1616-9436;

T.U.Y. 0000-0002-2344-7783;

T.S. 0000-0002-5733-6301;

O.Y. 0000-0003-0779-0001;

S.K. 0000-0002-4104-3985;

N.Z.U. 0000-0002-2133-3336;

N.Z.C. $0000-0002-0042-9742$.

Cite this paper as:

Güler SA, Yılmaz TU, Şimşek

T, Yirmibeşoğlu 0, Kırnaz S,

Utkan NZ, et al. Obesity and

Bariatric Surgery awareness

in the Kocaeli province, a

leading industrial city in

Turkey. Turk J Surg 201834

(3): 165-168.

Department of General Surgery, Kocaeli University School of Medicine, Kocaeli, Turkey

This study was presented at the $7^{\text {th }}$ National Endocrine Surgery, 23-26 April 2015, Antalya, Turkey.

\section{Corresponding Author}

Sertaç Ata Güler

e-mail:drsataguler@me.com

Received: 19.03.2017

Accepted: 12.06.2017

Available Online Date: 28.08.2018

CCopyright 2018

by Turkish Surgical Association

Available online at

www.turkjsurg.com
Objectives: An increase in the prevelance of obesity is a worldwide problem. It many serious health problems, especially cardiovascular diseases and type- 2 diabetes mellitus. Conservative therapies such as diet modification and exercise are the most preferable obesity treatments. Bariatric surgery is the most appropriate treatment in suitable patients. Several studies showed that a very low number of patients prefer bariatric surgery even though it would be appropriate. This study aimed to assess and raise awareness about the obesity level, its complications, and treatment methods, especially bariatric surgery among obese patients in Kocaeli, which is one of the most socioeconomically developed cities, as well as the leading industrial city in Turkey.

Material and Methods: A survey was designed to assess the knowledge about obesity, its complications, and bariatric surgery in the Kocaeli province. It was administered to 232 adult patients with a body mass index greater than 30 in different outpatient clinics where patients suffering obesity were treated.

Results: It has been seen that although the contribution factors and complications of obesity are well known, awareness of the body mass index was insufficient. Most of patients have tried to lose weight at least once and most patients have heard of bariatric surgery before. However, the details were not well known. The gastric band method is the most known method, and the most known risk of surgery was death. The main source of knowledge about bariatric surgery was television. The increasing body mass index affects patients' attitudes toward the surgery positively.

Conclusion: Knowledge of bariatric surgery is inadequate in the Kocaeli province, which is one of the most socioeconomically developed cities, as well as the leading industrial city in Turkey. More social responsibility projects and more objective elucidating via television and social media are also needed to increase the awareness of bariatric surgery.

Keywords: Bariatric surgery, knowledge, Kocaeli, obesity

\section{INTRODUCTION}

The rising prevalence of overweightness and obesity in several countries has been described as a global pandemic (1-3). Obesity and obesity-related diseases are replacing infectious diseases and malnutrition as the most significant health problem threatening the developing countries $(4,5)$. In 2008 , the World Health Organization (WHO) pointed out that the worldwide obesity has nearly doubled since 1980 (1). This increasing trend is also shown by Lancet in 2014: more than 2 billion people are overweight, and of these, approximately 670 million people are obese (2). According to the data from the Nutrition and Health Research in Turkey-2010 conducted by the Republic of Turkey Ministry of Health, the obesity prevalence is $20.5 \%$ among adult men and $41.0 \%$ among adult women.

World Health Organization uses the body mass index (BMI) as a quantitative parameter to define obesity and being overweight. It defines obesity as a BMI greater than or equal to $30 \mathrm{~kg} / \mathrm{m}^{2}$ and being overweight as a BMI greater than or equal to $25 \mathrm{~kg} / \mathrm{m}^{2}$. The main risk factors that contribute to obesity are genetics, environmental factors, physical inactivity, energy intake, fetal nutrition, and cultural elements $(1,5)$. Obesity and overweightness can cause a wide range of serious health conditions including cardiovascular diseases such as stroke, hypertension, and heart diseases, diabetes mellitus; musculoskeletal disorders such as osteoarthritis; some types of cancers; and sleep-breathing abnormalities $(1,5,6)$. Metabolic syndrome is also one of the most important complications of obesity, which comprises type 2 diabetes mellitus, hypertension, dyslipidemia, and insulin resistance (7-9). These obesity-related health problems cause significant treatment costs for these preventable diseases $(10,11)$.

When the prevention of obesity fails, the treatment of obesity may become unavoidable. These multidisciplinary treatment methods included lifestyle-based conservative interventions such as diet modification and exercise, medical approaches such as drug therapies, and bariatric surgery (10, 12). After previous unsuccessful attempts to lose weight with lifestyle-based conservative methods in patients with a BMI greater than $40 \mathrm{~kg} / \mathrm{m}^{2}$ or BMI ranging between 35 and $40 \mathrm{~kg} / \mathrm{m}^{2}$ with comorbidities, bariatric 
surgery becomes the most effective treatment for obesity. It achieves a significant weight loss and eases comorbid illness in eligible patients $(13,14)$. Sleeve gastrectomy and gastric bypass are the most common techniques to perform a bariatric surgery. However, globally, the number of eligible patients who undego bariatric surgery is low. Bariatric surgery is not well-known as an alternative weight loss method $(14,15)$.

Kocaeli was the Turkey's 11th most populous city (population $1,722,795)$ in 2014 , according to data of the Turkish Statistical Institute. More than 400 first-class and over 7,000 second- and third-class corporations are located in Kocaeli. Therefore, it is one of the leading industrial cities in Turkey. Kocaeli is also the

Table 1. Cohort distribution of the study

1511 appointments for 4 outpatient clinics

203 duplicated appointments

1308

232 missed the appointments

1076

224 patients did not sign the informed consent form

852

589 participants with body mass index $<30 \mathrm{~kg} / \mathrm{m}^{2}$

263

26 incomplete surveys

237

5 previously operated bariatric surgeries

232 final population of survey

Table 2. Demographic data of the patients

Body Mass Index $\left(\mathrm{kg} / \mathrm{m}^{2}\right)$

\begin{tabular}{|lcccc|} 
Variables & $30-34.9$ & $35-39.9$ & $\geq 40$ & $\mathbf{p}$ \\
\hline Gender & & & \multicolumn{2}{c}{0.113} \\
\hline Female & $89(50.0)$ & $63(35.4)$ & $26(14.6)$ & \\
\hline Male & $34(63.0)$ & $11(20.4)$ & $9(16.7)$ & \\
\hline
\end{tabular}

Outpatient Clinics

0.101

\begin{tabular}{|c|c|c|c|c|}
\hline $\begin{array}{l}\text { Endocrinology } \\
\text { and Metabolism }\end{array}$ & $54(50.5)$ & $35(32.7)$ & $18(16.8)$ & \\
\hline Diabetes and Obesity & $34(44.2)$ & $30(39.0)$ & $13(16.9)$ & \\
\hline General Surgery & $23(71.9)$ & $6(18.8)$ & $3(9.4)$ & \\
\hline Sleep Laboratory & $12(75.0)$ & $3(18.8)$ & $1(6.2)$ & \\
\hline Age groups (Year) & & & & 0.336 \\
\hline $18-25$ & $2(25.0)$ & $5(62.5)$ & $1(12.5)$ & \\
\hline $26-35$ & $18(66.7)$ & $6(22.2)$ & $3(11.1)$ & \\
\hline $36-45$ & $30(46.9)$ & $25(39.1)$ & $9(14.1)$ & \\
\hline $46-55$ & $39(48.8)$ & $24(30.0)$ & $17(21.2)$ & \\
\hline $56-65$ & $22(61.1)$ & $11(30.6)$ & $3(8.3)$ & \\
\hline $66-75$ & $10(66.7)$ & $3(20.0)$ & $2(13.3)$ & \\
\hline$>75$ & $2(100.0)$ & $0(0.0)$ & $0(0.0)$ & \\
\hline Total & 123 & 74 & 35 & \\
\hline
\end{tabular}

Datas are presented as $\mathrm{n}(\%)$ fourth most developed city after Istanbul, Ankara, and Izmir, according to the Socio-Economic Development Ranking Survey of Provinces and Regions (SEGE-2011) data of the Republic of Turkey Ministry of Development. Therefore, this study aimed to assess and raise the awareness level of obesity, its complications, and treatment methods, especially of bariatric surgery among obese patients in Kocaeli.

\section{MATERIAL AND METHODS}

This study started after obtaining an approval from The Ethical Committee of the Research Health Science Center, Kocaeli University. Then, 4 different outpatient clinics with the highest number of obese patients were determined by a preliminary study. The population of study consisted of patients who applied to these outpatient clinics (General Surgery, Endocrinology and Metabolism, Diabetes and Obesity Clinics, and Sleep Laboratory) during a 2-week period. The inclusion criteria for participation in the study were being over 18 years old, having a BMI greater than 30 , signing an informed consent form, and not treated by bariatric surgery. A weighting machine (Beko W1; Beko, Istanbul, Turkey) was used to measure the weight and height of patients. A survey had been administered to these patients. The survey included questions that assess patients' personal info, awareness about obesity, BMI, obesityrelated health problems, and weight loss methods, their previous experiences with weight loss, and their knowledge about bariatric surgery.

All statistical analyses were performed using the IBM Statistical Packages for the Social Sciences (SPSS) for Windows version 20.0 (IBM Corp.; Armonk, NY, USA). Kolmogorov-Smirnov tests were used to test the normality of data distribution. Continuous variables were expressed as median (IQR), and categorical variables were expressed as percentages. Comparisons of categorical variables between the groups were performed using the chi-squared test. The correlation between categorical variables was assessed by the Pearson correlation test, Kendal tau coefficient, and Cramer phi coefficient. A two-sided P-value $<0.05$ was considered to be statistically significant.

\section{RESULTS}

In two weeks, a total of 1511 appointments were made to the 4 outpatient clinics. The surveys were administered to 232 patients who were suitable according to the inclusion criteria (Table 1).

At the end of the study, it was seen that there was not a significant difference of distribution of patients' BMI between gender, applied outpatient clinic type, and age categories (Table 2).

The awareness of BMI was evaluated. Most of the patients $(55.2 \%)$ had never heard of the BMI before, and only $13.4 \%$ knew their own BMI value. Among the 104 who knew the meaning of BMI, only 41 (39.4\%) stated the obesity limit as $30 \mathrm{~kg} / \mathrm{m}^{2}$.

Some questions were about obesity-related health conditions. It showed that $79.7 \%$ of patients knew that diabetes, hypertension, and hyperlipidemia were complications of obesity. Heart attack (81.0\%), sleep apnea and respiratory problems (58.6\%), and joint diseases (69.0\%) were stated as obesity-related health problems by patients. 
Several weight loss methods had been tried by $86.2 \%$ of patients before. Among those patients, $89.0 \%$ tried diet modification, $72.0 \%$ exercise, and $9.0 \%$ used pharmacological methods to decrease their weight. After these attempts, $21.0 \%$ of them stated that they completely failed. On the other hand, $38.5 \%$ were partially successful, and $31.5 \%$ were successful. It has been observed that the most important factor of their failures was the lack of motivation (Table 3 ).

Knowledge of patients about bariatric surgery was assessed by the survey questions. Most of the patients (84.9\%) stated that they had heard of bariatric surgery as a treatment method, but they didn't know the details of this method, its techniques, and risks. On the other hand, $15.1 \%$ of patients had never heard about bariatric surgery before. The gastric band tech-

Table 3. Weight loss failure reasons

\begin{tabular}{|lc|}
\hline Weight Loss Failure Reasons & Ratio (\%) \\
\hline Resistance to weight loss & 40.3 \\
\hline Economical & 10.1 \\
\hline Lack of motivation & 54.6 \\
\hline Stress and fear of failing & 45.4 \\
\hline Family problems and lack of time & 26.9 \\
\hline Others & 36.1 \\
\hline
\end{tabular}

Table 4. Knowledge of surgical techniques

\begin{tabular}{|lc|}
\hline Surgical Techniques & Ratio (\%) \\
\hline Intragastric balloon & 37.2 \\
\hline Gastric band & 79.1 \\
\hline Sleeve gastrectomy & 51.2 \\
\hline Gastric bypass & 25.6 \\
\hline
\end{tabular}

Table 5. Knowledge about the complications of obesity surgery

\begin{tabular}{|lc|}
\hline Complications of Obesity Surgery & Ratio (\%) \\
\hline Death & 28.0 \\
\hline Anostomotic leak and ulcer & 11.2 \\
\hline Malnutrition & 7.3 \\
\hline Severe weight loss & 16.4 \\
\hline Gaining more weight & 5.6 \\
\hline Psychological problems & 10.3 \\
\hline
\end{tabular}

Table 6. Attitudes toward obesity surgery

\begin{tabular}{|c|c|c|c|c|}
\hline $\begin{array}{l}\text { Would you prefer } \\
\text { obesity surgery as } \\
\text { a treatment method? }\end{array}$ & $\begin{array}{c}\text { BMI: } \\
30-34.9\end{array}$ & $\begin{array}{c}\text { BMI: } \\
35-39.9\end{array}$ & $\begin{array}{l}\text { BMI: } \\
>40\end{array}$ & $\mathbf{p}$ \\
\hline No & $80(65.0)$ & $42(56.7)$ & $9(25.7)$ & \\
\hline Maybe, if it's necessary & $30(24.4)$ & $19(25.7)$ & $7(20.0)$ & \\
\hline Yes & 13 (10.6) & 13 (17.6) & $19(54.3)$ & \\
\hline Total & 123 & 74 & 35 & $<0.001$ \\
\hline
\end{tabular}

BMI: body mass index

Datas are presented as $\mathrm{n}(\%)$ nique $(79.1 \%)$ was the most known bariatric surgery method among the patients who knew that bariatric surgery was a treatment method (Table 4). When patients had been asked about the sources of their knowledge about bariatric surgery, it was observed that television (76.1\%) was the main source, and only $4.1 \%$ of patients stated that they had seen an informative brochure on this subject. Additionally, "death" was the most common answer (28.0\%) when the patients were asked about complications of bariatric surgery (Table 5). At the end, it was seen that an increasing BMI significantly affects the positive attitude toward bariatric surgery (Table 6).

\section{DISCUSSION}

Obesity is also one of the most important health problems in Turkey as it is in the rest of the world. This study was worked on to evaluate the latest data on obesity, its complications, treatment methods, and bariatric surgery in the leading Turkish industrial city, Kocaeli.

Even though there is no difference between the BMI ratios and gender categories, there were more women who participated in this study than men. This might be showing that obesity is more common in women. However, it shows that obesity is generally common in public because there is no difference between the BMI groups. The results are compatible with other studies in the literature that there are more cases in the 30-50 age category than in other age categories (16). These study data are similar to those from other studies that have been made in the country side of Turkey; however, ratios are higher when it is compared with other studies abroad $(16,17)$.

Obese patients applied to several different departments, so this shows that obesity does not belong to one department and that it requires a multidisciplinary approach. Contributing factors for obesity are observed as socio-economic status, dietary habits, and lack of physical activity. Moreover, the importance of self-motivation in weight loss has been shown in the literature $(18,19)$. As a matter of fact, both bariatric surgery's and other medical treatment's main goals are reducing the patient's energy intake and facilitating the weight loss process. Data showed that patients are usually willing to lose weight, but they also need additional assistance for that.

In this study, it was shown that most patients are aware of obesity and its complications. On the other hand, they are not well informed about the treatment methods. As the main definition of obesity, the BMI term is not well known. This is similar to other studies that were conducted in Turkey (17).

Unfortunately, most of the sources of patients' knowledge about bariatric surgery were non-medical sources. A similar issue is also apparent in other medical subjects. These sources are increasing the awareness of these treatment methods; however, it also is causing false or insufficient informing of individuals. It is necessary to inform people with more certain and correct information; furthermore, more health care professionals should be involved into these campaigns.

It was observed that patients' attitudes toward bariatric surgery is becoming more positive with a higher BMI. This expected result might be due to the failed weight loss attempts with other methods. Although most of the patients' attitudes are negative 
due to the complications of bariatric surgery, a considerable number of patients view bariatric surgery positively. Patients stated the death as the most known complication of bariatric surgery. The source of this excessive fear were mostly television and the internet. It has also been understood that there are not enough brochures about this subject. If the true numbers about the bariatric surgery complication were told to patients, their fear would be decreased (20). The most known method for bariatric surgery was observed as a gastric band. However, it is less preferable nowadays as it is seen in the literature (20).

\section{CONCLUSION}

This study has shown that the knowledge of bariatric surgery is inadequate in the Kocaeli province, which is one of the most socio-economically developed cities, as well as the leading industrial city in Turkey. Public informative brochures that comprise updated scientific data about obesity and bariatric surgery are needed. In addition, more social responsibility projects are also needed to increase the awareness of obesity and bariatric surgery.

Ethics Committee Approval: Ethics committee approval was received for this study from the Ethics Committee of the Kocaeli University Research Health Science Center.

Informed Consent: Written informed consent was obtained from patients who participated in this study.

Peer-review: Externally peer-reviewed.

Author Contributions: Concept - S.A.G., T.U.Y., N.Z.U.; Design - S.A.G., T.Ş., N.Z.C.; Supervision - O.Y., S.K., N.Z.U.; Resource - S.A.G., S.K., T.U.Y.; Materials - S.A.G., S.K., T.U.Y.; Data Collection and/or Processing - S.A.G., S.K., T.U.Y.; Analysis and/or Interpretation - S.A.G., O.Y., N.Z.C.; Literature Search - S.A.G., T.S., N.Z.U.; Writing Manuscript - S.A.G., S.K., N.Z.C.; Critical Reviews - S.A.G., T.Ş., O.Y.

Conflict of Interest: The authors have no conflicts of interest to declare.

Financial Disclosure: The authors declared that this study has recevied no financial support.

\section{REFERENCES}

1. WHO obesity and overweight fact sheet No.311; updated June 2016. Available from URL: http://www.who.int/mediacentre/factsheets/fs311/en/index.html.

2. Swinburn BA, Sacks G, Hall KD, McPherson K, Finegood DT, Moodie $M L$, et al. The global obesity pandemic: shaped by global drivers and local environments. Lancet 2011; 378: 804-814. [CrossRef]
3. Ng M, Fleming T, Robinson M, Thomson B, Graetz N, Margono $C$, et al. Global, regional, and national prevalence of overweight and obesity in children and adults during 1980-2013: a systematic analysis for the Global Burden of Disease Study 2013. Lancet 2014; 384: 766-781. [CrossRef]

4. Hossain P, Kawar B, El Nahas M. Obesity and diabetes in the developing world-a growing challenge. N Engl J Med 2007; 356: 213215. [CrossRef]

5. Peter GK. Obesity as a medical problem. Nature 2000; 404: 635643. [CrossRef]

6. Michael AK, Langley PC, Cox ER. A review of cost-of-illness studies on obesity. Clinical Therapeutics 1998; 20: 772-779. [CrossRef]

7. Erem C, Hacihasanoglu A, Deger O, Topbaş M, Hosver I, Ersoz HO, et al. Prevalence of metabolic syndrome and associated risk factors among Turkish adults: Trabzon MetS study Endocrine 2008; 33: 9-20. [CrossRef]

8. Atabek ME, Eklioğlu BS, Akyürek N. Reevaluation of the prevalence of metabolic syndrome in an urban area of Turkey. J Clin Res Pediatr Endocrinol 2013; 5: 50-54. [CrossRef]

9. Khunti K, Davies M. Metabolic syndrome. BMJ 2005; 331: 11531154. [CrossRef]

10. Schigt A, Gerdes VE, Cense HA, Berends FJ, van Dielen FM, Janssen $\mathrm{I}$, et al. Bariatric surgery is an effective treatment for morbid obesity. Neth J Med 2013; 71: 4-9.

11. Wang YC, McPherson K, Marsh T, Gortmaker SL, Brown M. Health and economic burden of the projected obesity trends in the USA and the UK. Lancet 2011; 378: 815-825. [CrossRef]

12. Bray GA, Tartaglia LA. Medicinal strategies in the treatment of obesity. Nature 2000; 404: 672-677. [CrossRef]

13. da Silva SS, da Costa Maia A. Obesity and treatment meanings in bariatric surgery candidates: a qualitative study. Obes Surg 2012; 22: 1714-1722. [CrossRef]

14. Sikorski C, Luppa M, Dame K, Brähler E, Schütz T, Shang E, et al. Attitudes towards bariatric surgery in the general public. Obes Surg 2013; 23: 338-345. [CrossRef]

15. Teo EY, Lew PS, Foo CS. Public perceptions of obesity and bariatric surgery in Singapore: a pilot study. Singapore Med J 2012; 53: 104-108.

16. Flegal KM1, Carroll MD, Kit BK, Ogden CL. Prevalence of obesity and trends in the distribution of body mass index among US adults, 1999-2010. JAMA 2012; 307: 491-497. [CrossRef]

17. Yilmaz TU. Obesity and gastrointestinal quality of life: A hospitalbased survey. Saudi J Obesity 2013; 1: 57-61. [CrossRef]

18. Elfhag $\mathrm{K}, \mathrm{Rössner} \mathrm{S}$. Who succeeds in maintaining weight loss? A conceptual review of factors associated with weight loss maintenance and weight regain. Obes Rev 2005; 6: 67-85. [CrossRef]

19. Williams GC, Grow VM, Freedman ZR, Ryan RM, Deci EL. Motivational predictors of weight loss and weight-loss maintenance. J Pers Soc Psychol 1996; 70: 115-126. [CrossRef]

20. Birkmeyer JD, Finks JF, O'Reilly A, Oerline M, Carlin AM, Nunn AR, et al. Surgical skill and complication rates after bariatric surgery. N Engl J Med 2013; 369: 1434-1442. [CrossRef] 